Brit. J. industr. Med., 1964, 21, 226

\title{
HEALTH EXAMINATIONS OF SENIOR STAFF IN INDUSTRY
}

\author{
BY \\ SUSAN H. MEADOWS \\ From the Department of Occupational Health and Applied Physiology, \\ London School of Hygiene and Tropical Medicine
}

(RECEIVED FOR PUBLICATION JANUARY 10, 1964)

\begin{abstract}
Of 228 senior staff participating in schemes for their health supervision who were asked for their opinions on the examinations, $26 \%$ said they had derived a lot of benefit, $53 \%$ a little, $20 \%$ no benefit, and $1 \%$ were unable to express an opinion. The degree of benefit felt was influenced by the number of routine examinations; age was relatively unimportant. Detection of hidden illness was considered the most important objective of the examinations, and the value of reassurance, usually in the absence of abnormal clinical findings, was mentioned by $65 \%$ of the respondents.

Ten per cent admitted to being worried by the idea of the examinations before they took place, and $32 \%$ said, retrospectively, that the examinations had reduced their concern about health. There was little criticism of the content of the examinations or the way the scheme was organized. The time given was considered to be of fundamental importance, as were also the personal qualities and interest of the examining doctor.
\end{abstract}

A recent enquiry by the Association of Industrial Medical Officers (1962) indicates that industry is increasingly accepting responsibility for the health of its senior employees. Out of 341 firms with occupational health services, 118 had schemes for the routine medical examination of their senior staff, the majority of which had been started in the last few years.

Most of the attempts to evaluate schemes of this type have been carried out in the United States of America, and many of these present evidence in their favour (Elsom, Spoont, and Potter, 1956; Saunders, 1954; Thompson and Staack, 1956). But this view is not universal, and the purpose and value of routine medical examinations are still debated. There are some doctors who believe that their justification lies in the increased opportunity for early diagnosis and treatment (British Institute of Management, 1955). Others believe that routine examinations have a value over and above the discovery of disease because they offer opportunities for health counselling and health maintenance and are particularly helpful to people with minor mental health problems (Browne, 1961; Cooper, 1955; Franco and Gerl, 1955; Keatinge, 1961; Wright and Levin, 1959).

It is also argued that there are disadvantages to such schemes. Some patients may fear being examined and, as a result, become over-anxious about their health (Bomford, 1963; Browne, 1961; Cullen, 1959). Others may be given a false sense of security (Chest and Heart Association, 1960; Transactions of the Association of Industrial Medical Officers, 1959). The opinions of both supporters and critics are generally based on impression rather than fact.

\section{The Groups Studied}

The present paper describes an opinion study of two groups of senior staff to seek their views on schemes for health supervision arranged by their firms. The first group included men employed by small firms in a newly-developed industrial area where the scheme had been operating for four years. The second group included employees of a large firm of building contractors whose scheme had started 11 years ago. Entry to both schemes was voluntary and governed by seniority and salary level. The number who refused to participate was less than $5 \%$. The examinations, which took from one to three hours, included detailed social, occupational, and medical histories followed by a clinical examination. They were repeated at fixed intervals with detailed questions about changes in home circumstances, occupation, and general way of life. 
Those in the first scheme were seen at intervals of approximately two years; those in the second at intervals of one year. Each examination was carried out by one of three doctors who made it clear at the outset that the examination was private and confidential, and that no discussion with the management would take place without the permission of the patient.

\section{Method}

Although the study was undertaken at the request of the examining doctors, it was done independently of them and management. Each subject was contacted individually, and the purpose of the enquiry was explained. A questionnaire was used in interviews lasting from 30 minutes to one and a half hours, and the respondent was encouraged to talk freely. The questions were designed to elicit attitudes towards the scheme generally together with the effect of the examinations on the respondent himself.

Of those in the first scheme, 114 out of a possible

- 116 were seen. The second scheme involved 197 employees, and from these a random sample of 118 was drawn, out of which 114 were seen. This gave a total response rate of $97 \%$. There were no major differences between the two groups in their attitudes towards the examinations, and in the subsequent analysis they are combined.

The majority $(92 \%)$ of the subjects were aged between 35 and 64 years (Table 4). A broad three- fold division* showed that $21 \%$ were supervising operatives, $45 \%$ were working as specialists, and the remainder were in higher direction. The three groups showed similar reactions to the examinations and will be considered together.

\section{Results}

General Attitudes.-As only $22(10 \%)$ had had other routine health examinations, attitudes were mostly based on the experience of the present scheme. Two hundred and one $(87 \%)$ thought that the idea of the schemes was good. The views of the 27 who did not think it was good may be summarized in these typical remarks, 'I use it because it's there; whether it does any good I don't know' and 'You know yourself whether you are reasonably fit.'

All were impressed by the thoroughness of the examinations and most thought it would not be

*Such broad groups are necessarily heterogeneous; the first included those supervising both on the factory floor and from an office; the second, those working primarily as specialists, e.g. estimators, second, those working primarily as specialists, e.g. estimators,
architects, and personnel managers; and the third, all directors and those with senior responsibility, e.g. departmental heads and location those with

5 possible for a doctor in the National Health Service to give so much time.

All but 10 of the subjects wanted the examinations to continue. Of these 10 , three saw no point in the examinations and seven were indifferent towards them. Some of the subjects in group I, who were seen first, volunteered that they would be prepared to pay for the examinations out of their own pocket. Those in group II were questioned specifically and $77 \%$ said they would pay if necessary.

In answer to the question, 'Do you feel that you have derived any benefit from the examination(s)?', about a quarter said they had derived a lot of benefit, and just over a half a little benefit (Table 1).

TABLE 1

DEGREE OF BENEFIT DERIVED BY 228 SENIOR STAFF FROM ROUTINE EXAMINATIONS

\begin{tabular}{l|r:r}
\hline \multirow{2}{*}{ Degree of Benefit } & \multicolumn{2}{c}{ Senior Staff } \\
\cline { 2 - 3 } & No. & $\%$ \\
\hline A lot & 59 & 25.9 \\
A little & 122 & 53.5 \\
None & 45 & 19.7 \\
Unable to express an opinion & 2 & 0.9 \\
\hline All & 228 & 100 \\
\hline
\end{tabular}

Comments ranged from the man who did not 'mind whether he went or not', to the frankly enthusiastic man who said that he would make alternative arrangements if the examinations were discontinued as he felt 'much relief from having them'. The following are illustrative of the comments of those who benefited a little: 'I suppose I must have derived some benefit, nothing was found to be wrong,' and 'It's good to know that someone's keeping a check on you'. The kinds of benefit derived by these men are summarized in Table 2 .

TABLE 2

TYPE OF BENEFIT DERIVED BY 181 SENIOR STAFF FROM ROUTINE EXAMINATIONS

\begin{tabular}{l|c}
\hline \multicolumn{1}{c|}{ Item } & $\begin{array}{c}\text { Frequency of } \\
\text { Occurrence }\end{array}$ \\
\hline General reassurance & 149 \\
Reassurance of those already concerned about & 22 \\
their health & 21 \\
Advice, e.g., on eating habits, exercise & 13 \\
Special investigations or treatment & 8 \\
Chance to discuss problems &
\end{tabular}

An entry was made each time one of them was mentioned, thus any one individual may be represented more than once.

Reassurance was the item which occurred most frequently. It usually stemmed from the satisfaction of a thorough examination in which no abnormality 
had been detected and has been separated from the reassurance given to those already feeling concern about their health. Most of those who benefited a lot remembered receiving more than general reassurance, whereas those who benefited a little only remembered being generally reassured. Advice on smoking, drinking, and eating habits, and the use of leisure was given frequently by the doctors but seldom mentioned by the patient. This may reflect the relative unimportance attached by the patient to advice which was perhaps not well communicated by the doctor, or his reluctance to remember advice which he found unpalatable.

Factors Influencing Attitudes.-The number of routine examinations clearly influenced the respondent's opinion as to whether he had benefited a lot or not at all. Of those examined once or twice, $16 \%$ said they had benefited a lot; this proportion rises to $54 \%$ among those examined seven or more times (Table 3). The relation between the number of examinations and the degree of benefit was found to be statistically significant at the 0.001 level of confidence. Remarks made during the course of

TABLE 3

DEGREE OF BENEFIT DERIVED BY 226 SENIOR STAFF ACCORDING TO NUMBER OF ROUTINE EXAMINATIONS*

\begin{tabular}{|c|c|c|c|c|}
\hline & \multicolumn{4}{|c|}{ No. of Examinations } \\
\hline & 1 or 2 & 3 or 4 & 5 or 6 & $7+$ \\
\hline $\begin{array}{l}\text { A lot } \\
\text { A little } \\
\text { Not at all }\end{array}$ & $\begin{array}{l}23(16 \%) \\
85(59 \%) \\
36(25 \%)\end{array}$ & $\begin{array}{c}10(32 \%) \\
15(49 \%) \\
6(19 \%)\end{array}$ & $\begin{array}{l}6(43 \%) \\
6(43 \%) \\
2(14 \%)\end{array}$ & $\begin{array}{c}20(54 \%) \\
16(43 \%) \\
1(3 \%)\end{array}$ \\
\hline All & $144(100 \%)$ & $31(100 \%)$ & $14(100 \%)$ & $37(100 \%)$ \\
\hline
\end{tabular}

the interviews support this finding. The subject who had had several examinations appeared to view the scheme as something more than a series of routine examinations designed to detect physical defects; he often discussed all manner of problems with the doctor and felt able to seek his advice when necessary. The man who had been seen only once or twice was often less sure of the state of his health and had less confidence in the doctor.

The older men appeared to benefit more than their younger colleagues, but the relation with age was not statistically significant (Table 4).

A further factor which may influence the individual's decision as to how much he has benefited is the medical treatment received as a result of the examinations. Nineteen of the 31 who remembered being referred to another doctor for
TABLE 4

DEGREE OF BENEFIT DERIVED BY 226 SENIOR STAFF FROM ROUTINE EXAMINATIONS ACCORDING TO AGE*

\begin{tabular}{|c|c|c|c|c|c|}
\hline & \multicolumn{5}{|c|}{ Age (yr.) } \\
\hline & $25-$ & $35-$ & $45-$ & $55-$ & $65-$ \\
\hline $\begin{array}{l}\text { A lot } \\
\text { A little } \\
\text { Not at all }\end{array}$ & $\begin{array}{l}1(14 \%) \\
5(72 \%) \\
1(14 \%)\end{array}$ & $\begin{array}{l}19(25 \%) \\
43(56 \%) \\
15(19 \%)\end{array}$ & $\begin{array}{l}21(23 \%) \\
46(50 \%) \\
25(27 \%)\end{array}$ & $\begin{array}{c}13(32.5 \%) \\
23(57.5 \%) \\
4(10 \%)\end{array}$ & $\begin{array}{r}5(50 \%) \\
5(50 \%) \\
-\quad-\end{array}$ \\
\hline All & $7(100 \%)$ & $77(100 \%)$ & $92(100 \%)$ & $40(100 \%)$ & $10(100 \%$ \\
\hline
\end{tabular}

treatment said thay had benefited a lot from the examinations.

Anxiety and Over-confidence.-Twenty-two subjects $(10 \%)$ admitted to being worried by the idea of the examination before it took place. Although very few had chosen not to participate in the scheme this figure might have been higher had the examinations been compulsory.

All subjects were asked at the interview whether they had worried about their health before the first examination and whether after the examinations they worried more, the same, or less. Of the 86 who worried about their health before being examined, 47 said they worried less after the examination(s) and only one worried more (Table 5).

TABLE 5

CHANGE IN ANXIETY ABOUT HEALTH IN 228 SENIOR STAFF AS A RESULT OF ROUTINE EXAMINATIONS

\begin{tabular}{|c|c|c|c|c|}
\hline \multirow{2}{*}{$\begin{array}{c}\text { Before } \\
\text { Examination }\end{array}$} & \multicolumn{4}{|c|}{ After Examinations } \\
\hline & More & Same & Less & All \\
\hline $\begin{array}{l}\text { A lot } \\
\text { A little } \\
\text { Not at all }\end{array}$ & $\begin{array}{l}\overline{1} \\
2\end{array}$ & $\begin{array}{r}3 \\
35 \\
113\end{array}$ & $\begin{array}{r}3 \\
44 \\
27\end{array}$ & $\begin{array}{r}6 \\
80 \\
142\end{array}$ \\
\hline All & 3 & 151 & 74 & 228 \\
\hline
\end{tabular}

One hundred and forty-two did not admit to having felt any anxiety about their health but 27 said subsequently that they had been reassured, whereas only two were made 'more' anxious by being examined.

Reassurance is the single item that occurs most frequently in answer to questions about the value of the schemes. The investigator was impressed by the ready belief that hidden illness would be detected. A possible degree of over-confidence was reflected in such statements, as 'The examination is a good thing logically; the individual need not then concern himself about his health' or 'You can leave 
it to the doctor to do the worrying'. Some, however, did not have implicit faith in the doctor's ability to detect disease. This is apparent from comments such as the following, 'I am reluctant to be completely reassured,' and 'I don't know how much they can deduce from such an examination'. The dangers of over-confidence were, to some extent, offset by the fact that the subjects were encouraged to see the doctor if symptoms developed or if they became concerned about their health; a number did return before the next routine examination was due.

Organization of the Scheme.-As laymen, the respondents were reluctant to criticize the organization of the scheme. The principal improvements suggested were inclusion of a chest radiograph (30)*, more frequent examinations (27)**, a fuller report to the patient (24), more attention to psychological issues (9), and greater regularity (6).

The majority $(77 \%)$ were happy with the intervals between examinations provided that they remained flexible and interim visits could be made. Only 10 felt the need to be seen six-monthly. These 10 included eight of those who appeared to regard the services of the physician as a substitute for those of their local doctor. This was not only convenient but preferable since they lacked faith in their own doctor. Eighteen of those seen referred to the passing of 'the traditional family doctor'. Satisfaction with the scheme was often in marked contrast to dissatisfaction with the National Health Service.

The personal qualities and interest of the physician were considered more important than a training in industrial medicine or a knowledge of industry. Few had first-hand experience of industrial medical officers, but most had formed ideas about their role and their relationship to management. One hundred and thirty-eight $(61 \%)$ said it would make no difference to them if the examining doctor was an industrial medical officer, but $82(36 \%)$ said it would make a difference. The remainder felt unable to express an opinion. Of the 82 who said it would make a difference, 74 preferred to be seen by a spzcialist, 26 because 'a specialist is always best' or because 'the best doctors don't go into industry', and 48 because 'he is more impartial'.

\section{Discussion}

All the men taking part in the first scheme and a random sample of $60 \%$ of those in the second scheme

* Mass miniature radiography had been available every two years to both groups.

**Most of these suggestions came from the group for which the interval between examination was two years. were chosen for study; $97 \%$ of the men selected were interviewed, and it seems reasonable to believe that the opinions expressed are representative of the participants in the two schemes. It is not possible to say how representative they are of other senior employees, but when the two groups were examined separately their opinions of the schemes were very similar in spite of differences in the type of industry and the areas in which they are employed. Neither differences between doctors nor the occupational status of the subject appeared to influence the opinions expressed.

Most of the men considered the detection of illness the main objective of the scheme. Since they were aware of the stresses of modern industry and the illnesses of middle age, as depicted in the press and high-lighted by the death of colleagues, it is not surprising that many said they derived benefit from being found fit.

Advice was mentioned infrequently as a benefit of the examinations. It may be that, unlike the search for hidden illness, it is accepted as part of the doctor's stock-in-trade and is not thought worthy of comment.

Many of the men indicated during the course of the interviews that they enjoyed having 'someone to talk to'. Some saved up their little aches and pains, others their queries on smoking and eating. That those who had had several examinations felt more benefit suggests that prolonged contact with someone who knows his problems is itself of value.

It was suggested that the period between examinations might be more flexible. It is possible that once confidence has been established between doctor and patient, the patient might be left to see the doctor when he feels the need. There is little indication from this study that a service of this kind would be abused.

Certain dangers are said to be associated with these examinations. As far as can be judged from this study, the examinations caused very little anxiety. Reassurance led to some over-confidence but not to an amount which could be regarded as dangerous.

I am indebted to the firms who made this investigation possible, to the senior staff who co-operated so willingly, to the physicians concerned, and to the staff of the Harlow Industrial Health Service and the Personnel Department of Richard Costain Limited.

Thanks are due to Miss Joan Walford for criticism and statistical help and to Dr. R. Acheson, Lord Taylor, Dr. S. Chave, and Dr. H. B. Wright for their comments on the paper in draft.

Particular thanks are due to Professor R. S. F. Schilling for his help and encouragement at all stages of the investigation. 


\section{REFERENCES}

Association of Industrial Medical Officers. Research Advisory Committee and Dingwall Fordyce, I. (1962). Trans. Ass.

industr. med. Offrs, 11, 169.
Bomford, R. R. (1963). Proc. roy. Soc. Med., 56, 316.

British Institute of Management (1955). Executive Health Schemes, Information Summary No. 63 .

Browne, R. C. (1961). Health in Industry. Arnold, London.

Chest and Heart Association (1960). The Health of Business Executives. Trans 1st Conf., 1959. London.
Cooper, A. R. (1955). Brit. J. industr. Med., 12, 71.

Cullen, N. H. (1959). Trans. Ass, industr, med Offrs, 9, 94.

Elsom, K. A., Spoont, S., and Potter, H. P. (1956). Industr. Med. Surg., $25,367$.

Franco, S. C., and Gerl, A. J. (1955). Ibid., 24, 161.

Keatinge, G. F. (1961). Trans. Ass. industr. med. Offrs, 11, 4.

Saunders, G. M. (1954). Arch. industr. Hyg., 9, 133.

Thompson, C. E., and Staack, H. F. (1956). Industr. med. Surg., 25, 175.

Transactions of the Association of Industrial Medical Officers (1959).

Wright, H. B., and Levin, A. (1959). The Director (Sept.), 12, 192. 